УДК 342.571

\title{
ДОПОЛНИТЕЛЬНЫЕ (ФАКУЛЬТАТИВНЫЕ) КОНСТИТУЦИОННО-ПРАВОВЫЕ ГАРАНТИИ РЕАЛИЗАЦИИ ПРАВА ГРАЖДАН РОССИИ НА ОСУЩЕСТВЛЕНИЕ ОБЩЕСТВЕННОГО КОНТРОЛЯ: КОНСТИТУЦИОННО-ПРАВОВОЙ АНАЛИЗ
}

Гончаров В.В. Юридическая консалтинговая корпорация «Ассоциация независимых правозащитников», г. Краснодар, Российская Федерация, niipgergo2009@mail.ru

Настоящая статья посвящена исследованию понятия и видов дополнительных (факультативных) конституционно-правовых гарантий реализации права граждан Российской Федерации на осуществление общественного контроля. Объект исследования - общественные отношения, возникающие в процессе реализации права граждан Российской Федерации на осуществление общественного контроля. Цель исследования: определить понятие конституционно-правовых гарантий реализации прав граждан в Российской Федерации, провести их классификацию. Задачи исследования: 1) дать определение понятия конституционно-правовых гарантий реализации прав граждан в Российской Федерации; 2) провести классификацию конституционно-правовых гарантий на две группы: базовых (основных); дополнительных (факультативных); 3) дать определение понятию дополнительных (факультативных) конституционно-правовых гарантий реализации права граждан Российской Федерации на осуществление общественного контроля; 4) провести их классификацию. Полученные результаты могут быть использованы как в учебной и научной, так и в практической деятельности, в том числе в законотворчестве.

Ключевые слова: дополнительные (факультативные) конституционно-правовые гарантии; Российская Федерация; народовластие; участие граждан в управлении делами государства; общественный контроль; юридические гарантии; обеспечение; права; свободы; субъекты.

DOI: $10.21779 / 2224-0241-2019-30-2-32-39$

UDC 342.571

\section{ADDITIONAL (OPTIONAL) CONSTITUTIONAL AND LEGAL GUARANTEES OF THE RIGHT OF RUSSIAN CITIZENS TO EXERCISE PUBLIC CONTROL: CONSTITUTIONAL AND LEGAL ANALYSIS}

Goncharov V.V., Legal consulting corporation «Association of independent human rights defenders», Krasnodar, Russian Federation, niipgergo2009@mail.ru

This article is devoted to the study of additional (optional) constitutional and legal guarantees of the right of citizens of the Russian Federation to exercise public control. The process of realization of rights, freedoms and legitimate interests of a person and a citizen faces many obstacles of a subjective and objective nature. An important role in overcoming them is played by the institution of legal guarantees, ensuring the implementation, protection and protection of the rights, freedoms and legitimate interests of man and citizen. The most legally significant guarantees of the rights, freedoms and legitimate interests of man and citizen - constitutional and legal guarantees-are enshrined in the Constitution of the Russian Federation and the current legislation. In turn, the constitutional and legal guarantees of realization of the right of citizens of Russia to exercise public control are subdivided taking into account the level of the normative legal act fixing them, influence on degree of possibility of implementation of the right to public control, and also compliance to the rights making structure of this composite right, on the basic (basic) and additional (optional). The obtained results can be used both in educational and scientific, and in practice, including in law-making.

Key words: additional (optional) constitutional and legal guarantees; Russian Federation; democracy; participation of citizens in the management of state Affairs; public control; legal guarantees; security; rights; freedoms; subjects.

DOI: $10.21779 / 2224-0241-2019-30-2-32-39$

Для того чтобы реализовать любое право человека и гражданина необходимо задействовать определённый юридический механизм по переводу права как идеальной категории в реальную дей- ствительность, отраженную в общественных отношениях. Однако данный переход сопряжен со значительным количеством препятствий объективного и субъективного характера: с противодействием 
других лиц процессу реализации права; с неисполнением или ненадлежащим исполнением участниками правоотношений встречных обязанностей, корреспондирующих реализовываемому праву; с несовершенством нормативно-правовой базы, особенно на региональном и муниципальном уровне, которая не содержит необходимых нормативноправовых актов, позволяющих осуществить полноценную и своевременную реализацию права.

Все это требует разработки и реализации специального правового механизма, позволяющего обеспечить реализацию права человека и гражданина. Ключевая роль и место в нем отведена системе юридических гарантий, посредством которых и обеспечивается полноценная и своевременная реализация прав и свобод человека и гражданина, а также обеспечивается стабильность в правовом регулировании общественных отношений.

Важное место в системе юридических гарантий, в свою очередь, занимают конституционные правовые гарантии, которые обеспечивают реализацию наиболее существенных и важных прав и свобод человека и гражданина.

Под конституционно-правовой гарантией следует понимать закрепленную в Конституции Российской Федерации и действующем законодательстве единообразную систему действующих на территории всей страны обязательных условий, принципов, методов, приемов и механизмов, позволяющих обеспечить: полноценную реализацию конституционно-установленных прав, свобод и законных интересов граждан и юридических лиц, их защиту и восстановление в случае нарушения (в том числе и посредством деятельности национальных и международных органов правосудия); повышение в обществе ценности института права; поднятие уровня правовой культуры населения; формирование непримиримости к любым типам нарушений правовых предписаний.

Представляется, что конституционноправовые гарантии реализации прав граждан следует классифицировать на две группы: базовые (основные); дополнительные (факультативные).

В качестве критериев отнесения конституционно-правовых гарантий реализации прав граждан к категории базовых (основных) выступает:

1) невозможность реализации прав граждан без них, либо наличие существенных затруднений, искажающих результат подобной реализации, делающих его непригодным для субъекта (носителя) указанных прав;

2) их закрепление в Конституции Российской Федерации и федеральном законодательстве.

В качестве критериев отнесения конституционно-правовых гарантий реализации прав граждан к категории дополнительных (факультативных) выступает:

1) их соотношение с конкретными правами, посредством которых граждане Российской Федерации реализуют свое право;
2) их закрепление, как правило, в законах субъектов Российской Федерации, региональном законодательстве, а также муниципальных нормативно-правовых актах.

Необходимость в дополнительных (факультативных) конституционно-правовых гарантиях реализации права граждан Российской Федерации на осуществление общественного контроля является предметом широкой дискуссии в отечественной научной и учебной правовой литературе $[1 ; 2$, c. 50 ; $3 ; 4]$ и обусловлена рядом причин.

Во-первых, Российская Федерация является федеративным государством и согласно пунктам «б» и «н» части 1 статьи 72 Основного закона страны защита прав и свобод человека и гражданина, а также установление общих принципов организации системы органов государственной власти и местного самоуправления, относятся к совместному ведению Российской Федерации и субъектов Российской Федерации.

Данная норма детализирована в части 2 статьи 1 Федерального закона от 06.10.1999 г. № 184-Ф3 «Об общих принципах организации законодательных (представительных) и исполнительных органов государственной власти субъектов Российской Федерации», согласно которой органы государственной власти субъекта Российской Федерации обеспечивают реализацию прав граждан на участие в управлении делами государства [5], а также в части 4 статьи 3 Федерального закона от 06.10.2003 г. № 131-Ф3 «Об общих принципах организации местного самоуправления в Российской Федерации», которая закрепляет право федеральных органов государственной власти и органов государственной власти субъектов Российской Федерации по обеспечению государственных гарантий прав населения на осуществление местного самоуправления [6].

Это означает, что конституционноправовые гарантии, обеспечивающие защиту права граждан Российской Федерации на общественный контроль, устанавливаются не только на уровне Российской Федерации, но и в субсидиарном (дополнительном) порядке на уровне российских регионов. Кроме того, субъекты Российской Федерации уполномочены на закрепление дополнительных гарантий по осуществлению общественного контроля в отношении органов региональной государственной власти и местного самоуправления, а также их должностных лиц.

Эту конституционную норму детализирует и раскрывает часть 1 статьи 2 Федерального закона от 21.07.2014 г. №212-Ф3 «Об основах общественного контроля в Российской Федерации», включившая в правовую основу общественного контроля наряду с федеральными нормативноправовыми актами законы и иные нормативные правовые акты субъектов Российской Федерации, а также муниципальные нормативными правовые акты. 
В связи с этим А.В. Чуклин совершенно справедливо отмечает: «Важно, чтобы конкретизация дополнительных гарантий реализации конституционных прав и свобод... осуществлялась преимущественно законами субъекта Российской Федерации, а не подзаконными актами. В значительной степени это позволит установить стабильно действующие дополнительные гарантии реализации конституционных прав и свобод, адекватные общественным отношениям, существующим в регионе» [7, с. 89].

При этом Федеральный закон от 21.07.2014 г. №212-Ф3 установил, что в ряде областей государственного управления (например, деятельности в области обеспечения обороны страны и безопасности государства, общественной безопасности и правопорядка, деятельности полиции, органов следствия, прокуратуры и судов, а также деятельности, связанной с исполнением наказаний, контролем за оборотом наркотических средств и психотропных веществ, содержанием детей-сирот и детей, оставшихся без попечения родителей, оказанием психиатрической помощи) регулирование общественного контроля осуществляется только федеральными законами.

Но и в этом случае, федеральный законодатель делегировал ряд полномочий, в том числе и по установлению гарантий реализации прав граждан на осуществление общественного контроля в отдельных областях государственного управления, например, органам местного самоуправления.

Так, согласно ряду статей (в частности, $14.1,15.1)$ Федерального закона от 06.10.2003 г. № 131-Ф3 «Об общих принципах организации местного самоуправления в Российской Федерации» в числе прав органов местного самоуправления на решение вопросов, не отнесенных к вопросам местного значения, закреплено оказание поддержки общественным наблюдательным комиссиям, осуществляющим общественный контроль за обеспечением прав человека и содействие лицам, находящимся в местах принудительного содержания [6]. При этом данное право выступает в роли дополнительной (факультативной) конституционно-правовой гарантии реализации прав граждан России на осуществление общественного контроля.

Во-вторых, базовые (основные) конституционно-правовые гарантии общественного контроля, хотя и представляют собой систему обязательных условий, принципов, методов, приемов и механизмов, позволяющих осуществить его реализацию, защиту, восстановление и профилактику возможных нарушений в дальнейшем, но не в состоянии учесть в полной мере региональную и местную специфику регулирования правоотношений в области общественного контроля, особенно в части осуществления контроля за органами региональной государственной власти и местного самоуправления, а также их должностными лицами.
В-третьих, реализация общественного контроля на уровне российских регионов и муниципальных образований, участие в этом процессе общественных палат субъектов Российской Федерации и муниципальных образований, а также иных субъектов общественного контроля, сформированных в соответствии с региональным законодательством и муниципальными актами, регулирующими вопросы общественного контроля, требует их постоянного совершенствования и развития. При этом реализация конкретных прав субъектов общественного контроля на региональном и местном уровне требует постоянного совершенствования дополнительных (факультативных) гарантий, их обеспечивающих.

Представляется, что дополнительные (факультативные) конституционно-правовые гарантии общественного контроля можно классифицировать по ряду оснований:

1. В зависимости от вида нормативноправового акта, их устанавливающего, они подразделяются на закреплённые: в федеральном законодательстве; региональных законах (включая конституции и уставы субъектов Российской Федерации); иных нормативно-правовых актах.

Так, например, в качестве дополнительной (факультативной) гарантии реализации прав граждан Российской Федерации на общественный контроль выступает закрепленная в статье 2 Федерального закона от 21.07.2014 г. №212-Ф3 «Об основах общественного контроля в Российской Федерации» возможность принятия на уровне субъектов Российской Федерации и муниципальных образований законов и иных нормативно-правовых актов, регулирующих вопросы общественного контроля на уровне регионов и муниципальных образований, которые включены в правовую основу общественного контроля в России.

Региональные и муниципальные органы власти, реализуя данную дополнительную (факультативную) гарантию вправе принимать детализирующие ее законы субъектов Российской Федерации, нормативно-правовые акты регионального и муниципального уровня. При этом часть дополнительных (факультативных) гарантий по реализации права граждан Российской Федерации на общественный контроль закрепляется на уровне субъектов Российской Федерации непосредственно в их уставах и конституциях. Например, часть 2 статьи 19 Устава Свердловской области закрепляет в качестве подобной гарантии институт Уполномоченного по правам человека в Свердловской области, который играет важную роль в реализации итоговых документов, подготавливаемых субъектами общественного контроля по факту проведённых мероприятий общественного контроля на территории области [8].

Однако, большая часть дополнительных (факультативных) гарантий закрепляется в региональных законах, посвящённых регулированию 
общественного контроля, а также деятельности общественных палат на уровне субъекта Российской Федерации. Так, Закон Свердловской области от 19.12.2016 г. № 151-О3 «Об общественном контроле в Свердловской области» наряду с многочисленными нормами, детализирующими основные (базовые) гарантии, предусмотренные федеральным законодательством, содержит значительное количество и дополнительных (факультативных) гарантий. Например, он закрепил статус губернатора Свердловской области как гаранта, обеспечивающего защиту прав и свобод человека и гражданина в сфере организации и осуществления общественного контроля и организующего исполнение законов Свердловской области, регулирующих отношения в сфере организации и осуществления общественного контроля [9].

2. В зависимости от того, обеспечивают ли они реализацию права граждан на общественный контроль в целом, либо отдельные конкретные права, составляющие его содержание, они подразделяются на гарантии широкого профиля и специфические. Так, например, в качестве конституционно-правовой гарантии широкого профиля можно выделить предусмотренную Законом Краснодарского края от 25.12.2015 г. № 3305-К3 «Об общественном контроле в Краснодарском крае» в пункте 2 части 6 статьи 9 обязанность объектов общественного контроля, расположенных на территории Краснодарского края учитывать предложения, рекомендации и выводы, содержащиеся в итоговых документах, подготовленных по результатам общественного контроля, в случае, если в течение одного календарного года по одному и тому же вопросу общественного контроля два и более субъекта общественного контроля представят одинаковые предложения и рекомендации, не противоречащие нормативным правовым актам Российской Федерации, нормативным правовым актам Краснодарского края, муниципальным нормативным правовым актам [10].

В свою очередь, в качестве специфической конституционно-правовой гарантии можно выделить предусмотренное в части 5 статьи 19 Закона Свердловской области от 19.12.2016 г. № 151-О3 «Об общественном контроле в Свердловской области» право субъектов общественного контроля на проведение общественных экспертиз сроком до 120 дней со дня объявления о проведении такой экспертизы [9].

Ряд авторов выделяет среди разновидностей дополнительных конституционно-правовых гарантий (по порядку их закрепления в региональном законодательстве), наряду с общими и конкретными гарантиями, обеспечивающими реализацию права граждан на общественный контроль в целом, либо отдельные конкретные права, составляющие его содержание, еще и смешанные гарантии, посредством которых обеспечивается реализация нескольких смежных прав [11]. Однако в дан- ной классификации представляется спорным основание для разграничения смешанных и общих гарантий в связи с тем, что последние также обеспечивают реализацию нескольких прав, составляющих содержание права граждан на общественный контроль.

В связи с этим, представляется более логичной классификация дополнительных гарантий, представленная А.В. Чуклиным, основанная на количестве конституционных прав и свобод, обеспечение которых осуществляется с помощью общих дополнительных гарантий и конкретных (специальных) дополнительных гарантий: «Общие дополнительные гарантии обеспечивают реализацию нескольких конституционных прав и свобод, конкретные (специальные) дополнительные гарантии направлены на реализацию определенного конституционного права или свободы» [12, с. 48].

В свою очередь, А.Н. Волчанская проводит классификацию дополнительных (факультативных) конституционно-правовых гарантий не с позиции количества прав, которые они обеспечивают, а с привязкой их к правовому статусу личности, в связи с чем, считает возможным дополнительно выделить, наряду с общими и специальными гарантиями, еще и индивидуальные конституционноправовые гарантии [13].

Однако представляется, что данная классификация носит спорный характер в связи с тем, что дополнительные гарантии реализации права на общественный контроль имеют не конкретные граждане (либо их представители, в том числе - и в лице субъектов общественного контроля), а отдельные их категории. При этом данные гарантии могут бить либо специфическими, либо широкого профиля.

Например, в качестве специфической дополнительной (факультативной) гарантии можно считать предусмотренное частью 5 статьи 21 Закона Республики Татарстан от 27.04.2017 г. № 24ЗРТ «Об общественной палате Республики Татарстан» право членов Общественной палаты, не согласных с принятым решением Общественной палаты, изложить в письменной форме свое особое мнение, которое прилагается к решению Общественной палаты и направляется вместе с ним [14].

В свою очередь, в качестве дополнительной (факультативной) гарантии широкого профиля можно выделить предусмотренную статьей 20 Устава Свердловской области обязанность органов государственной власти Свердловской области, иных государственных органов Свердловской области, органов местного самоуправления муниципальных образований, расположенных на территории Свердловской области, в соответствии с федеральными законами и законами Свердловской области создавать условия для развития гражданского общества и его институтов [8].

3. В зависимости от видов форм общественного контроля они подразделяются на обеспе- 
чивающие: общие формы общественного контроля (общественный мониторинг, общественную проверку, общественную экспертизу); формы взаимодействия институтов гражданского общества с государственными органами и органами местного самоуправления (общественные обсуждения, общественные (публичные) слушания и иные формы).

Так, в качестве дополнительной (факультативной) конституционно-правовой гарантии при осуществлении отдельных форм общественного контроля можно выделить, например, предусмотренное частью 3 статьи 24.2 Закона Московской области от 10.04.2009 г. № 30/2009-О3 «Об Общественной палате Московской области» право членов Общественной палаты Московской области на свободный доступ при проведении общественных проверок в проверяемый орган или организацию согласно распорядку работы этого органа или организации по списку лиц, уполномоченных на проведение общественной проверки, согласованному с руководителем соответствующего органа или организации, а в случае его отсутствия - с лицом, исполняющим его обязанности [15].

В свою очередь, к дополнительной (факультативной) конституционно-правовой гарантии, обеспечивающей формы взаимодействия институтов гражданского общества с государственными органами и органами местного самоуправления в Волгоградской области, можно отнести предусмотренную частью 1 статьи 9 Закона Волгоградской области 30.12.2015 г. № 240-ОД «Об осуществлении общественного контроля в Волгоградской области» обязанность проведения общественных обсуждений по вопросам закупок товаров, работ, услуг для обеспечения государственных нужд Волгоградской области в случае, если начальная (максимальная) цена контракта либо цена контракта, заключаемого единственным поставщиком (подрядчиком, исполнителем), составляет от 50 млн. рублей до 1 млрд. рублей включительно [16]. При этом, порядок общественного обсуждения закупок в таких случаях устанавливается нормативным правовым актом Губернатора Волгоградской области.

4. В зависимости от характера принадлежности полномочий, в рамках которых они принимаются, их можно классифицировать на принимаемые в рамках собственных полномочий либо в рамках делегированных полномочий. Ряд авторов дают более расширенную классификацию дополнительных гарантий по данному классифицирующему признаку. Например, А.В. Чуклин считает, что дополнительные гарантии в зависимости от характеристики полномочий субъекта Российской Федерации можно классифицировать на: «дополнительные гарантии реализации конституционных прав и свобод человека и гражданина установленные в рамках полномочий органов государственной власти субъекта Российской Федерации по предме- там исключительного ведения субъектов Российской Федерации; собственных полномочий органов государственной власти субъекта Российской Федерации по предметам совместного ведения Российской Федерации и субъектов Российской Федерации; делегированных органам государственной власти субъекта Российской Федерации федеральных полномочий по предметам совместного ведения Российской Федерации и субъектов Российской Федерации; делегированных органам государственной власти субъекта Российской Федерации федеральных полномочий по предметам исключительного ведения Российской Федерации; полномочий, право осуществления которых предоставлено органам государственной власти субъекта Российской Федерации федеральными законами» $[17$, c. 9$]$.

5. В зависимости от того, какая имеется связь между дополнительными (факультативными) конституционно-правовыми гарантиями и конкретными правами, составляющими содержание права граждан Российской Федерации на общественный контроль, которое они обеспечивает, они подразделяются на прямые и косвенные. При этом прямые гарантии обусловливают непосредственную связь своего содержания с реализацией данного права, а косвенные - лишь опосредованную. Одна и та же гарантия может выступать в роли прямой и косвенной по отношению к процессу реализации разных конституционных прав граждан. Например, предусмотренная частью 1 статьи 9 Закона Волгоградской области 30.12.2015 г. № 240-ОД «Об осуществлении общественного контроля в Волгоградской области» обязанность Губернатора Волгоградской области утвердить своим постановлением порядок общественного обсуждения по вопросам закупок товаров, работ, услуг для обеспечения государственных нужд Волгоградской области является прямой дополнительной (факультативной) конституционно-правовой гарантией для реализации субъектами общественного контроля своего права на осуществление общественного обсуждения закупок в целом, и косвенной гарантией для общественного обсуждения конкретной закупки продукции, превышающей сумму в 50 млн. рублей [16].

6. В зависимости от содержащихся в них способах правового регулирования дополнительные (факультативные) конституционно-правовые гарантии можно классифицировать на запрещающие, дозволяющие и обязывающие.

В свою очередь, В.А. Лебедев считает, что данные гарантии и формулируются в форме запретов, дозволений и предоставлений [18, с. 22]. Однако представляется, что данная классификация не учитывает обязывающих гарантий. Например, в качестве обязывающей дополнительной (факультативной) конституционно-правовой гарантии выступает предусмотренное в части 4 статьи 10 Закона Свердловской области от 19.12.2016 г. № 151- 
О3 «Об общественном контроле в Свердловской области» информирование в обязательном порядке общественными инспекторами, общественными экспертами или иными лицами субъектов общественного контроля в письменной форме соответствующих субъектов общественного контроля в случае возникновения личной заинтересованности, которая приводит или может привести к конфликту интересов между субъектом и объектом общественного контроля [9].

В отдельных случаях обязывающие гарантии носят не конкретизирующий (общий) характер. Так, Закон Ростовской области от 01.03.2017 г. № 1025-3С «Об Общественной палате Ростовской области» закрепил в качестве обязывающей (факультативной) конституционно-правовой гарантии при проведении общественного контроля обязанность Законодательного Собрания Ростовской области принимать по результатам заслушивания ежегодного доклада Общественной палаты постановление, а органов государственной власти Ростовской области - учитывать рекомендации, в нем содержащиеся, при планировании социальноэкономического и культурного развития Ростовской области [19].

В качестве примера дозволяющей дополнительной (факультативной) конституционноправовой гарантии можно привести предусмотренное в пункте 1 части 1 статьи 14 Закона Свердловской области от 22.03.2018 г. № 32-О3 «Об Общественной палате Свердловской области» право Общественной палаты Свердловской области осуществлять общественный контроль над деятельностью территориальных органов федеральных органов исполнительной власти [20].

Наиболее распространенной формой в Российской Федерации исторически являются запрещающие дополнительные (факультативные) конституционно-правовые гарантии.

Например, Закон Краснодарского края от 25.12.2015 г. № 3305-К3 «Об общественном контроле в Краснодарском крае» в части 9 статьи 4 закрепил в качестве подобной гарантии запрет членов общественной инспекции и группы общественного контроля на осуществление общественного контроля органов и организаций, а также издаваемых ими актов и принимаемых ими решений в случае, если их близкий родственник является должностным лицом проверяемого органа или организации либо он или его близкий родственник ранее работали в этом органе или организации [10].

7. Кроме того, дополнительные (факультативные) конституционно-правовые гарантии можно разделить на: обеспечивающие право граждан на осуществление общественного контроля в целом либо в конкретных отраслях государственного управления (экологический общественный контроль; контроль за реализацией избирательных прав; контроль за реализацией прав лицами, нахо- дящимися в местах принудительного содержания и т.п.).

Так, в соответствии с частями 2 и 3 статьи 6 Закона Республики Дагестан от 13.03.2015 г. № 19 «Об общественном экологическом контроле» в качестве отраслевой дополнительной (факультативной) конституционно-правовой гарантии реализации прав граждан Российской Федерации на общественный контроль выступает обязанность уполномоченных органов государственной власти рассматривать результаты общественного экологического контроля, оформляемые в виде актов обследования [21].

В заключение можно сделать следующие выводы.

1. Под конституционно-правовой гарантией следует понимать закрепленную в Конституции Российской Федерации и действующем законодательстве единообразную систему действующих на территории всей страны обязательных условий, принципов, методов, приемов и механизмов, позволяющих обеспечить: полноценную реализацию конституционно-установленных прав, свобод и законных интересов граждан и юридических лиц, их защиту и восстановление в случае нарушения (в том числе и посредством деятельности национальных и международных органов правосудия); повышение в обществе ценности института права; поднятие уровня правовой культуры населения; формирование непримиримости к любым типам нарушений правовых предписаний.

2. Конституционно-правовые гарантии с учётом уровня нормативно-правового акта, их закрепляющего, влияния на степень возможности осуществления права на общественный контроль, а также соответствия правам, составляющим структуру данного сложносоставного права, подразделяются на базовые (основные) и дополнительные (факультативные).

3. Дополнительные (факультативные) конституционно-правовые гарантии общественного контроля можно классифицировать в зависимости:

а) от вида нормативного правового акта, их устанавливающего (на федеральные, региональные, прочие);

б) от того, обеспечивают ли они реализацию права граждан на общественный контроль в целом либо отдельные конкретные права, составляющие его содержание (на гарантии широкого профиля и специфические);

в) от видов форм общественного контроля (на обеспечивающие общие формы общественного контроля и формы взаимодействия институтов гражданского общества с государственными органами и органами местного самоуправления);

г) от характера принадлежности полномочий, в рамках которых они принимаются (на принимаемые в рамках собственных полномочий либо в рамках делегированных полномочий); 
д) от того, какая имеется связь между ними и конкретными правами, составляющими содержание права граждан Российской Федерации на общественный контроль, которое они обеспечивает (на прямые и косвенные);

е) от содержащихся в них способах правового регулирования (на запрещающие, дозволяю- щие и обязывающие); ж) от целевой направленности (на обеспечивающие право граждан на осуществление общественного контроля в целом либо в конкретных отраслях государственного управления).

\section{Литература}

1. Егоров С.C. Гарантии прав и свобод человека и гражданина в конституционном (уставном) законодательстве субъектов Российской Федерации: автореф. дис. ... канд. юрид. наук. М., 2013.

2. Чуклин A.B. Принципы установления субъектами Российской Федерации дополнительных гарантий реализации конституционных прав и свобод человека и гражданина // Конституционное и муниципальное право. 2016. № 11. С. 50-53.

3. Ишеков К.А. Реализация конституций и уставов субъектов Российской Федерации органами государственной власти: конституционно-правовое исследование: дис. ... д-ра юрид. наук. Саратов, 2014.

4. Чурсина E.B. Разграничение полномочий между органами государственной власти Российской Федерации и ее субъектов по предметам совместного ведения: конституционно-правовое исследование: дис. ... канд. юрид. наук. Краснодар, 2005.

5. Об общих принципах организации законодательных (представительных) и исполнительных органов государственной власти субъектов Российской Федерации: федер. закон Рос. Федерации от 6 окт. 1999 г. № 184-Ф3: в ред. от 1 мая 2019 г. Доступ из справ.-правовой системы «КонсультантПлюс».

6. Об общих принципах организации местного самоуправления в Российской Федерации: федер. закон Рос. Федерации от 6 окт. 2003 г. № 131-Ф3: в ред. от 1 мая 2019 г. Доступ из справ.-правовой системы «КонсультантПлюс».

7. Чуклин A.B. Правовые проблемы установления субъектами Российской Федерации дополнительных гарантий реализации конституционных прав и свобод человека и гражданина // Правоприменение. 2017. Т. 1. № 4. С. 89-90.

8. Устав Свердловской области: Закон Свердловской области от 23 дек. 2010 г. №105-O3. URL: http://docs.cntd.ru/document/895280236. (дата обращения: 01.01.2019).

9. Об общественном контроле в Свердловской области: Закон Свердловской области от 19 дек. 2016 г. № 151-О3: в ред. от 26 февр. 2018 г. [Электронный pecypc]. URL: http://docs.cntd.ru/document/429088309 (дата обращения: 01.01.2019).

10. Об общественном контроле в Краснодарском крае: Закон Краснодарского края от 25 дек. 2015 г. № 3305-К3: в ред. от 3 марта 2017 г. [Электронный pecypc]. URL: http:/docs.cntd.ru/document/432809870 (дата обращения: 01.01.2019).

11. Водкина Т.П. Конституционное право граждан на жилище (теоретические основы и нормативно-правовые особенности в субъектах Российской Федерации): дис. ... канд. юрид. наук. М., 2011.

12. Чуклин A.B. Проблемы классификации дополнительных гарантий реализации конституционных прав и свобод человека и гражданина, устанавливаемых субъектами Российской Федерации // Проблемы права. 2016. № 1 (55).

13. Волчанская А.Н. Государственные гарантии защиты прав человека: теоретический аспект: дис. ... канд. юрид. наук. Саратов, 2013.

14. Об общественной палате Республики Татарстан: Закон Республики Татарстан от 27 апр. 2017 г. № 24-3РТ: в ред. от 17 июня 2019 г. Доступ из справ.-правовой системы «КонсультантПлюс».

15. Об Общественной палате Московской области: Закон Московской области от 10 апр. 2009 г. № 30/2009-О3 (утратил силу).

16. Об осуществлении общественного контроля в Волгоградской области: закон Волгоградской области 30 дек. 2015 г. № 240-ОД. URL: http://docs.cntd.ru/document/432835737 (дата обращения: 01.01.2019).

17. Чуклин A.B. Дополнительные гарантии реализации конституционных прав и свобод человека и гражданина, устанавливаемые субъектами Российской Федерации: автореф. дис. ... канд. юрид. наук Екатеринбург, 2018.

18. Лебедев B.A. Конституционный статус человека и гражданина в Российской Федерации // Проблемы права. 2011. № 5(31). С. 22-25.

19. Об Общественной палате Ростовской области: закон Ростовской области от 1 марта 2017 г. № 1025-3. URL: http://docs.cntd.ru/document/444997048 (дата обращения: 01.01.2019).

20. Об Общественной палате Свердловской области: закон Свердловской области от 22 марта 2018 г. № 32-O3. URL: http://docs.cntd.ru/document/543548426 (дата обращения: 01.01.2019). 
21. Об общественном экологическом контроле: закон Республики Дагестан от 13 марта 2015 г. № 19: в ред. 7 марта 2019 г. URL: http://docs.cntd.ru/document/424040197 (дата обращения: 01.01.2019).

\section{References}

1. Egorov S.S. Garantii prav i svobod cheloveka i grazhdanina v konstitutsionnom (ustavnom) zakonodatel'stve sub"ektov Rossiiskoi Federatsii: avtoref. dis. ... kand. yurid. nauk. M., 2013.

2. Chuklin A.V. Printsipy ustanovleniya sub"ektami Rossiiskoi Federatsii dopolnitel'nykh garantii realizatsii konstitutsionnykh prav i svobod cheloveka i grazhdanina // Konstitutsionnoe i munitsipal'noe pravo. 2016. № 11. S. 5053.

3. Ishekov K.A. Realizatsiya konstitutsii i ustavov sub"ektov Rossiiskoi Federatsii organami gosudarstvennoi vlasti: konstitutsionno-pravovoe issledovanie: dis. ... d-ra yurid. nauk. Saratov, 2014.

4. Chursina E.V. Razgranichenie polnomochii mezhdu organami gosudarstvennoi vlasti Rossiiskoi Federatsii i ee sub"ektov po predmetam sovmestnogo vedeniya: konstitutsionno-pravovoe issledovanie: dis. ... kand. yurid. nauk. Krasnodar, 2005.

5. Ob obshchikh printsipakh organizatsii zakonodatel'nykh (predstavitel'nykh) i ispolnitel'nykh organov gosudarstvennoi vlasti sub"ektov Rossiiskoi Federatsii: feder. zakon Ros. Federatsii ot 6 okt. 1999 g. № 184-FZ: v red. ot 1 maya 2019 g. Dostup iz sprav.-pravovoi sistemy «Konsul'tantPlyus».

6. Ob obshchikh printsipakh organizatsii mestnogo samoupravleniya v Rossiiskoi Federatsii: feder. zakon Ros. Federatsii ot 6 okt. 2003 g. № 131-FZ: v red. ot 1 maya 2019 g. Dostup iz sprav.-pravovoi sistemy «Konsul'tantPlyus».

7. Chuklin A.V. Pravovye problemy ustanovleniya sub"ektami Rossiiskoi Federatsii dopolnitel'nykh garantii realizatsii konstitutsionnykh prav i svobod cheloveka i grazhdanina // Pravoprimenenie. 2017. T. 1. № 4. S. 8990.

8. Ustav Sverdlovskoi oblasti: Zakon Sverdlovskoi oblasti ot 23 dek. 2010 g. №105-OZ. URL: http://docs.cntd.ru/document/895280236 (data obrashcheniya: 01.01.2019).

9. Ob obshchestvennom kontrole v Sverdlovskoi oblasti: Zakon Sverdlovskoi oblasti ot 19 dek. 2016 g. № 151-OZ: v red. ot 26 fevr. 2018 g. [Elektronnyi resurs]. URL: http://docs.cntd.ru/document/429088309 (data obrashcheniya: 01.01.2019).

10. Ob obshchestvennom kontrole v Krasnodarskom krae: Zakon Krasnodarskogo kraya ot 25 dek. 2015 g. № 3305-KZ: v red. ot 3 marta 2017 g. [Elektronnyi resurs]. URL: http://docs.cntd.ru/document/432809870 (data obrashcheniya: 01.01.2019).

11. Vodkina T.P. Konstitutsionnoe pravo grazhdan na zhilishche (teoreticheskie osnovy i normativnopravovye osobennosti v sub"ektakh Rossiiskoi Federatsii): dis. ... kand. yurid. nauk. M., 2011.

12. Chuklin A.V. Problemy klassifikatsii dopolnitel'nykh garantii realizatsii konstitutsionnykh prav i svobod cheloveka i grazhdanina, ustanavlivaemykh sub"ektami Rossiiskoi Federatsii // Problemy prava. 2016. № 1 (55).

13. Volchanskaya A.N. Gosudarstvennye garantii zashchity prav cheloveka: teoreticheskii aspekt: dis. ... kand. yurid. nauk.Saratov, 2013.

14. Ob obshchestvennoi palate Respubliki Tatarstan: Zakon Respubliki Tatarstan ot 27 apr. 2017 g. № 24-ZRT: v red. ot 17 iyunya 2019 g. Dostup iz sprav.-pravovoi sistemy «Konsul'tantPlyus».

15. Ob Obshchestvennoi palate Moskovskoi oblasti: Zakon Moskovskoi oblasti ot 10 apr. 2009 g. № 30/2009-OZ (utratil silu).

16. Ob osushchestvlenii obshchestvennogo kontrolya $\mathrm{v}$ Volgogradskoi oblasti: zakon Volgogradskoi oblasti 30 dek. 2015 g. № 240-OD. URL: http://docs.cntd.ru/document/432835737 (data obrashcheniya: 01.01.2019).

17. Chuklin A.V. Dopolnitel'nye garantii realizatsii konstitutsionnykh prav i svobod cheloveka i grazhdanina, ustanavlivaemye sub"ektami Rossiiskoi Federatsii: avtoref. dis. ... kand. yurid. nauk Ekaterinburg, 2018.

18. Lebedev V.A. Konstitutsionnyi status cheloveka i grazhdanina v Rossiiskoi Federatsii // Problemy prava. 2011. № 5(31). S. 2225.

19. Ob Obshchestvennoi palate Rostovskoi oblasti: zakon Rostovskoi oblasti ot 1 marta 2017 g. № 1025-Z. URL: http://docs.cntd.ru/document/444997048 (data obrashcheniya: 01.01.2019).

20. Ob Obshchestvennoi palate Sverdlovskoi oblasti: zakon Sverdlovskoi oblasti ot 22 marta 2018 g. № 32-OZ. URL: http://docs.cntd.ru/document/543548426 (data obrashcheniya: 01.01.2019).

21. Ob obshchestvennom ekologicheskom kontrole: zakon Respubliki Dagestan ot 13 marta $2015 \mathrm{~g}$. № 19: v red. 7 marta 2019 g. URL: http://docs.cntd.ru/document/424040197 (data obrashcheniya: 01.01.2019). 